\title{
MANHAJ IJTIHAD PADA ASPEK POLITIK
}

\author{
Gani Jumat'. \\ Fakultas Syariah IAIN Palu \\ Email: ganijumat@iainpalu.ac.id
}

\begin{abstract}
This article discusses the application of the manhaj or the ijtihad method to the political aspects of the state. The focus of the problem is, can ijtihad be applied to the political aspects of the state, not only to the aspects of fiqh or religious law? Some Muslims still understand that the position of ijtihad is limited to the aspect of fiqh alone. for example, matters of the law of religious observances, marriage and other social institutions). During the period of the Prophet Muhammad, when he moved to Medina, the Prophet made a political commitment as a nation and state involving various ethnic, ethnic and religious layers in Medina. This political commitment is called Shahifah Madinah or Watsiqah Madinah (Medina charter), which consists of 47 articles as the basis for living together with the nation and state. Until now, in a very modern world, the Medina Charter is still considered the most modern political monumental ijtihad ever practiced by the Prophet Muhammad. Based on the above thought background, ijtihad can be used as a method of approach in formulating the concepts of state politics.
\end{abstract}

\section{Keywords: Manhaj, Ijtihad, Politics}

\begin{abstract}
Abstrak
Artikel ini membahas tentang penerapan manhaj atau metode ijtihad pada aspek politik kenegaraan. fokus permasalahannya adalah, apakah ijtihad dapat diterapkan pada aspek politik kenegaraan tidak hanya pada aspek fiqh atau hukum keagamaan? sebagian kalangan Muslim kedudukan ijtihad tersebut masih dipahami hanya dipraktekkan terbatas pada aspek fiqh semata. misalnya persoalan hukum peribadatan keagamaan, kawin mawin, dan pranata sosial lainnya). Pada periode Rasulullah Saw, ketika hijrah ke Madinah, Rasulullah membuat komitmen politik berbangsa dan bernegara yang melibatkan berbagai lapisan etnis, suku dan agama di Madinah. Komitmen politik itu disebut dengan Shahifah Madinah atau Watsiqah Madinah (piagam Madinah), yang terdiri dari 47 pasal sebagai dasar hidup bersama berbangsa dan bernegara. Sampai masa kini, pada dunia yang sangat modern, Piagam Madinah masih tetap dianggap sebagai ijtihad monumental politik yang paling modern, yang pernah dilakukan oleh Nabi Muhammad Saw. Berdasarkan latar belakang pemikiran di atas, maka ijtihad dapat dijadikan sebagai salah satu metode pendekatan dalam merumuskan konsepkonsep politik kenegaraan.
\end{abstract}

\footnotetext{
${ }^{1}$ Penulis merupakan Dekan Fakultas Syariah IAIN Palu
} 


\section{Kata Kunci: Manhaj, Ijtihad, Politik}

\section{A. Pendahuluan}

Kebanyakan masyarakat merasa dan mengetahui, atau bahkan meyakini, bahwa hubungan antara agama dan politik dalam Islam sudah sangat jelas. Hubungan Islam dan Negara sudah menjadi masalah nasional kita sejak awal kemerdekaan. Hal itu sudah menjadi kisah klasik dalam khazanah kehidupan politik di Indonesia. Yaitu bahwa antara keduanya terkait erat secara tidak terpisahkan, sekalipun dalam segi pendekatan teknis dan praktis dapat dibedakan. Agama adalah wewenang shahib al-syari'ah (pemilik syari'ah), yaitu Rasulullah Saw, melalui wahyu atau berita suci yang diterimanya dari Allah s.w.t. sedangkan masalah politik, adalah bidang wewenang kemanusiaan, khususnya sepanjang menyangkut masalah-masalah teknis struktural dan prosedural. ${ }^{2}$ Dalam hal ini, besar sekali peranan pemikiran ijtihad (penalaran) manusia.

Persoalan penting antara bidang agama dan bidang politik (atau bidang kehidupan duniawi manapun) ialah bahwa dari segi etis, khususnya segi tujuan yang merupakan jawaban atau pertanyaan "untuk apa" tidak dibenarkan lepas dari pertimbangan nilai-nilai keagamaan. Hal itu diharapkan agar tumbuh kegiatan politik bermoral tinggi atau berakhlak mulia. Inilah makna bahwa politik tidak dapat dipisahkan dari agama. Tetapi dalam hal susunan formal atau strukturnya serta segi-segi praktis dan teknisnya, politik adalah wewenang manusia, melalui pemikiran rasionalnya (yang dapat dipandang sebagai suatu jenis ijtihad).

Dalam konteks itulah politik dapat dibedakan dari agama. Maka dalam segi struktural dan prosedural politik itu, dunia Islam sepanjang sejarahnya mengenal berbagai variasi dari masa ke masa dari kawasan ke kawasan, tanpa satupun dari variasi itu dipandang secara doktrinal yang absah (kecuali masa khulafa al-Rasyidin). Hubungan antara agama dan poltik yang tidak terpisahkan

${ }^{2}$ Nurcholish Madjid, Agama dan Politik dalam Islam, Jurnal Pemikiran Islam Paramadina, Volume I Nomor 1 ( Jakarta; Paramadina, 1998) h. 49. 
itu dengan jelas sekali terwujud dalam masyarakat Madinah. Muhammad saw selama sekitar sepuluh tahun di kota hijrah itu tampil sebagai seorang penerima berita suci(sebagai nabi) dan seorang pemimpin masyarakat politik (sebagai kepala Negara). Fazlur Rahman, tokoh Neomodernisme Islam, membenarkan bahwa masyarakat Madinah yang diorganisir Nabi itu merupakan suatu Negara dan pemerintahan yang membawa kepada terbentuknya suatu umat Muslim. ${ }^{3}$

Dalam menjalankan peran sebagai seorang nabi, beliau adalah seorang tokoh yang tidak boleh dibantah, karena mengemban tugas suci dengan mandat dan wewenang suci. Sedangkan dalam menjalankan peran sebagai seorang kepala Negara, beliau melakukan musyawarah sesuai dengan perintah Allah Swt, yang dalam musyawarah itu beliau tidak jarang mengambil pendapat orang lain dan meninggalkan pendapat pribadi sendiri. Sebab dalam hal peran sebagai kepala negara atau pemimpin masyarakat itu pada dasarnya beliau melakukan ijtihad. Jika dalam kenyataan hasil ijtihad beliau hampir selamanya merupakan yang terbaik di antara para anggota masyarakat beliau, maka hal itu harus diterangkan sebagai akibat logis segi keunggulan kemampuan pribadi beliau selaku seorang manusia. Dan pengakuan memang banyak diberikan orang, baik dari kalangan Islam maupun bukan Islam, bahwa beliau adalah seorang jenius. Gabungan antara kesucian dan kesempurnaan tugas kenabian di satu pihak dan kemampuan pribadi yang sangat unggul di pihak lain telah membuat Nabi Muhammad saw, seorang tokoh yang paling berhasil dalam sejarah umat manusia. ${ }^{4}$

Gejala penerapan ijtihad pada aspek politik di Indonesia, telah terjadi sejak semula yaitu ketika the founding father, para pendiri Negara ini berdebat secara a lot dan melelahkan untuk menentukan idiologi atau dasar Negara Indonesia.

${ }^{3}$ Fazlur Rahman, The Islamic Consept of State, dalam John J. Donohue dan L. Esposito, (eds.) Islam in Transition, Muslim Perspective, Oxford University Press, New York, 1982, h. 261 dan dikutip oleh J. Suyuthi Pulungan dalam Prinsip-prinsip pemerintahan dalam Piagam Madinah Ditinjau dari Pandangan Al-Quran, (Jakarta: Raja Grafindo kerjasama dengan LSIK Jakarta, 1994) h. 2

${ }^{4}$ Misalnya, sebagaimana ditulis oleh Michael Hart dalam bukunya tentang Seratus Tokoh Dunia, yang telah diterjemahkan ke dalam Bahasa Indonesia. 
Semula kelompok Islam (termasuk Muhammadiyah dan Nahdlatul Ulama) menginginkan Islam menjadi dasar Negara, sedangkan kelompok lain menginginkan Pancasila menjadi dasar Negara. Yang pertama biasa disebut kelompok Islam dan yang kedua biasa disebut kelompok nasionalis. Menurut Salahuddin Wahid, masih ada pihak ketiga, yaitu kelompok komunis yang untuk sementara ketika itu, masih mendukung Pancasila. ${ }^{5}$ Tulisan ini akan berusaha menjelaskan bagaimana konsep ijtihad sebagai metode pendekatan istinbath hukum dapat di terapkan tidak hanya pada bidang sosial keagamaan tetapi juga pada aspek sosial politik kenegaraan.

\section{B. Rumusan dan Batasan Masalah}

Berdasarkan latar belakang pemikiran di atas, maka ijtihad dapat dijadikan sebagai salah satu metode pendekatan dalam merumuskan konsepkonsep politik kenegaraan. Dengan demikian maka fokus permasalahannya adalah, apakah ijtihad dapat diterapkan pada aspek politik kenegaraan tidak hanya pada aspek fiqh atau hukum keagamaan?

Fokus masalah tersebut dapat dipetakan dalam dua sub masalah, yaitu;

1. Apakah makna dan ruang lingkup ijtihad?

2. Bagaimanakah penerapan ijtihad pada aspek politik ?

\section{Pembahasan}

Muhammad Iqbal ${ }^{6}$ salah seorang pemikir muslim kontemporer terkemuka dari anak benua India, menegaskan bahwa Islam menolak pandangan statis

${ }^{5}$ Baca lebih lanjut dalam tulisan Salahuddin Wahid, "Dinamika Hubungan Islam dan Negara Di Indonesia”, Tashwirul Afkar Jurnal Refleksi Pemikiran Keagamaan dan Kebudayaan (Edisi Khusus; Jakarta: Lembaga Kajian dan Pengembangan Sumberdayamanusia (LAKPESDAM NU kerjasama dengan DEPARTEMEN AGAMA RI, 2004) h. 70

${ }^{6}$ Sir Muh. Iqbal, dilahirkan di Sialkot, punjab, pada taggal 21 April 1938. Menurut pengamatan Iqbal, kemunduran umat Islam disebabkan oleh karena hancurnya Baghdad, timbulnya faham fatalisme sikap jumud. Agar supaya umat Islam maju maka umat Islam perlu mengembangkan konsep Ijtihad dan faham dinamisme Islam. Hukum Islam menurut Iqbal, tidak 
tentang rotasi alam semesta ini, karena ia berjalan sesuai dengan sunnatullah, dan sebaliknya mendukung pandangan yang dinamis. Dia berargumentasi bahwa menurut kosmologi Islam, penciptaan dan pengaturan bumi dan segala isinya ini bersifat progresif evolusioner, ia melanjutkan statemennya yang cemerlang, seperti dikutip oleh Haidar Bagir, bahwa prinsip gerak yang sebenarnya dalam Islam adalah apa yang disebut dengan Ijtihad. ${ }^{7}$

Ijtihad dalam pengertian di atas, adalah upaya untuk mengantisipasi tantangan-tantangan baru yang terus menerus dimunculkan oleh sifat evolusioner kehidupan. Dengan demikian, maka satu persatu "energi potensial" atau potensi “intelektual” manusia sang madataris Tuhan akan terurai dan pada gilirannya akan melahirkan peningkatan kualitas hidupnya menuju tercapainya maksud dan tujuan penciptaan.

1. Makna dan Ruang Lingkup Ijtihad

Adapun makna ijtihad, dapat dilihat dalam penjelasan al-Raghib alIsfahany berikut ini

Ijtihad terdiri dari rumpun huruf (ج) ج ه berarti bersungguh-sungguh. Jadi makna ijtihad adalah mengerahkan kemampuan pikiran dan jiwa secara sungguh-sungguh untuk mengeluarkan suatu hukum dari tempat yang sulit. ${ }^{8}$

Dalam makna yang lain ijtihad juga dapat berarti :

bersifat statis tetapi berkembang sesuai dengan perkembangan zaman. Lihat Dewan Redaksi Ensiklopedi Islam, jilid 2 (Cet. III; Jakarta : PT. Ichtiar Baru Van Hoeve, 1994), h. 235-237.

${ }^{7}$ Disadur dari Haidar Bagir, yang mengutip dari Reconstruction of Religions Though In Islam kitab bavan, (India, 1981), h. 147-148.

${ }^{8}$ Kata Ijtihad, berasal dari ijtahada-yajtahidu-ijtihadan, dari akar kata, Jahada, yang berarti bersungguh-sungguh atau kerja keras dengan sekuat tenaga. Maka Ijtihad, adalah "upaya mengerahkan kemampuan pikiran dan jiwa untuk mengeluarkan suatu hukum dari tempat yang sulit”. Lihat al-Raghib al-Isfahani, Mufradaat al-Fazh al-Quran, (Cet. Pertama: Beirut Daar alQalam, 1992 M), h. 208. Bandingkan dengan Muhammad Idris al-Marbawy, Qamus Idris alMarbawy Araby Malayu, (Singapura: Daar al-Ulum al-Islamiah, 1353 H), h. 112, Ahmad Ibn Faris, dalam Maqayis Al-Lughah, h. 112 dan Al-Fairuzzabadi dalam Al-Qamus al-Muhith, h. 207 serta Lois Ma'luf dalam Al-munjid Fi al-Lughah Wa al-A'lam, (Beirut: Daar al-Qalam, 1411 H/ $1991 \mathrm{M})$, h. 106 
Berusaha dengan sungguh-sungguh dalam bidang fiqh, berarti mengerahkan segala tenaga dan pikiran untuk menyelidiki dan mengeluarkan (mengistinbathkan) hukum-hukum yang terkandung di dalam al-Qur'an dengan syarat-syarat tertentu. ${ }^{9}$

Sedangkan menurut istilah para ahli ushul fiqh antara lain dijelaskan oleh

Imam al-Syaukany dan Imam al-Zarkasyi :

Ijtihad adalah mencurahkan semua kemampuan untuk mencari syara' (hukum Islam) yang bersifat operasional dengan istinbath (mengambil kesimpulan hukum). ${ }^{10}$

Dalam Kamus Istilah Agama, dijelaskan secara lebih luas dan operasional:

Ijtihad adalah suatu usaha yang dilakukan para ahli dengan sungguhsungguh mengerahkan segala daya kemampuan rohani dan akal pikiran yang rasional, menggali masalah keislaman dengan berdasarkan al-Qur'an dan hadis (yang shahih) serta dengan qiyas yang tepat, untuk menetapkan suatu hukum syar'i. ${ }^{11}$

Berdasarkan analisis di atas, maka kita dapat berkata bahwa ijtihad tidak lain dari suatu aktivitas berpikir rasional, sistimatis dan radikal untuk mengeluarkan hukum syara' baik yang berkaitan dengan persoalan sosial keagamaan maupun sosial keduniaan untuk kemaslahatan umat manusia. Dengan kata lain bahwa makna dan substansi ijtihad tersebut tidak saja pada aspek hukum, tetapi juga pada bidang yang lain, seperti dibidang politik, tasawuf sains dan teknologi.

Dalam kajian makalah ini perlu ditegaskan bahwa di Indonesia, istilah ijtihad lebih identik dalam makna fiqh ansiech, padahal penemuan seorang fisikawan muslim Abd. Latif Salam, bahwa sumber gaya yang menggerakkan alam semesta ini hanya bersumber dari satu kekuatan tunggal yaitu Allah. Begitu pula penemuan bola lampu listrik oleh Thomas Alfa Edison, setelah melalui proses berfikir yang mendalam dalam bidang sains. Bukankah ini adalah ijtihad

\footnotetext{
${ }^{9}$ Ensiklopedi Islam, op.cit., h. 183.

${ }^{10}$ Ibid.

${ }^{11}$ M. Shodiq, Kamus Istilah Agama, Edisi khusus, (Jakarta : Bonaciptama, 1991), h. 133.Bandingkan dengan Muhammad Abu Zahrah, Ilm Ushul al-Fiqh,
} 
dibidang sains ? bahkan peristiwa "orgasme spiritual" yang dialami oleh seorang sufi ${ }^{12}$ pada wilayah "Mahabbah dan Ma'rifatullah", juga merupakan hasil sebuah proses ijtihad. Jadi, makna ijtihad yang telah penulis jelaskan di atas, adalah dalam arti sempit.

Dengan demikian, kita dapat berkata bahwa ruang lingkup dan wilayah garapan ijtihad tidak hanya dalam wilayah kajian fiqh tetapi juga dalam disiplin ilmu pengetahuan lain, yang menjadi kebutuhan pokok umat manusia termasuk aspek politik kenegaraan. Akan tetapi penulis tidak bermaksud membicarkan makna ijtihad dalam arti luas tersebut melainkan hanya bersifat informatif tentang esensi dan substansi ijtihad sebagai sebuah ikhtiar manusia dalam memecahkan problematika kehidupannya.

2. Kasus Penerapan Ijtihad pada aspek Politik.

a. Pancasila dan Undang-Undang Dasar 1945

Pembahasan tentang perlunya dasar Negara, diawali oleh Widiodiningrat, Ketua BPUPKI, yang mengusulkan pentingnya melakukan pembahasan untuk merumuskan landasan filosofis Negara yang akan dibentuk. Landasan ini merupakan sebuah filsafat dan sekaligus spirit yang kuat yang mendasari struktur Negara merdeka yang harus dibangun kelak. ${ }^{13}$ Kelompok nasionalis, yang diwakili Soekarno, dalam sidang BPUPKI 1 Juni 1945, mengusulkan Pancasila

\footnotetext{
${ }^{12}$ Ibnu Taimiah, salah satu dari tokoh pembaharu Islam, menyebutkan bahwa ijtihad juga digunakan dalam bidang tasawuf dan lain-lain, seperti ditegaskan : Sebenarnya mereka (kaum sufi) adalah mujtahid-mujtahid dalam masalah kepatuhan, sebagaimana mujtahid-mujtahid lain ... dan pada hakikatnya mereka (kaum sufi di Bashrah), dalam masalah ibadah dan ahwal (hal ihwal) ini adalah mujtahid-mujtahid seperti halnya dengan tetangga mereka di Kufah yang juga mujtahidmujtahid dalam hukum, tatanegara dan lain-lain Lihat Syaikh Ibn Taimiah, Majmu' Fatawaa pada pembahasan Kitab al-Tasawwuf, juz 3 (Beirut : Dar al-Arabiah, 1418 H / 1997 M), h. 18

${ }^{13}$ BPUPKI melaksanakan dua kali persidangan; tanggal 29 Mei sampai 1 Juni 1945, dan dari tanggal 10 hingga 17 Juli 1945. Panitia sembilan yang diketuai oleh Ir. Soekarno pada tanggal 22 Juni 1945 berhasil menetapkan Rancangan Pembukaan Undang-Undang Dasar yang didalamnya tercantum dasar dan tujuan Negara. Naskah rancangan pembukaan itu dikenal dengan sebutan "Piagam Jakarta atau Jakarta Charter". Seluruh rancangan undang-undang dasar Negara berhasil diselesaikan pada persidangan kedua. Lihat Ahmad Sukardja, Piagam Madinah Dan Undang-Undang Dasar 1945 Kajian Perbandingan Tentang Dasar Hidup Bersama Dalam Masyarakat Yang Majemuk ( Cet. Pertama; Jakarta: UI-Press, 1995 ), h. 43
} 
sebagai dasar Negara. Dengan Pancasila yang diusulkan itu, Soekarno menempatkan nasionalisme sebagai prinsip pertama. Di sini Soekarno secara tegas mendefenisikan nasionalisme bukan semata-mata hanya sebuah keyakinan atau kesadaran rakyat yang disatukan ke dalam kelompok, satu bangsa, tetapi juga sebagai kesatuan anatara rakyat dengan tanah airnya. ${ }^{14}$ Di sini jelas Soekarno menempatkan nasionalisme sebagai prinsip utama sekaligus sebagai tulang punggung kesatuan dan persatuan Negara. ${ }^{15}$

Negara yang diusulkan oleh kelompok nasionalis sebagaimana tampak dalam proposal soekarno adalah Negara yang memungkinkan semua kelompok untuk terwadahi ${ }^{16}$ Dalam pemikiran Soekarno itu, tampak jelas ia menekankan bahwa nasionalisme harus merupakan landasan filosofis Negara, dan untuk itu maka Negara ini harus memungkinkan semua kelompok untuk terlibat dalam setiap proses politik yang terjadi. Demikian juga kelompok Islam, partisipasinya sangat diharapkan, dengan tntu saja menghormati kepentingan kelompok lain.

\section{b. Piagam Jakarta}

Sebagai reaksi terhadap pemikiran Soekarno, kelompok Islam mengusulkan agar Islam menjadi dasar Negara. Usulan-usulan ini disampaikan baik dalam siding-sidang BPUPKI maupun dalam sidang-sidang Majlis Konstituante. Mohammad Natsir, seorang pemimpin Partai Masyumi, berargumen

14 Soekarno, "Lahirnya Pancasila", dalam Pancasila Dasar Negara, ( Jakarta: Intidaya Press, 1986), h.144-145

${ }^{15}$ Ada dua landasan fundamental yang dibangun Soekarno, yaitu landasan politik dan landasan etika. Prinsip nasionalisme, dalam pandangan Soekarno, berfungsi sebagai basis politik dari Pancasila, sedangkan prinsip Ketuhanan sebagai basis etikanya. Dengan demikian, maka yang hendak ditegaskan Soekarno adalah bahwa dalam sebuah negara yang pertama-tama harus dibangun adalah fondasi politik dan baru setelah itu menyusul fondasi etikanya. Lihat Artikel yang ditulis oleh Ellyasa KH Darwis, Amandemen dan Perebutan Makna Pasal 29 UUD 45 Suatu Penghampiran Histories -Struktural, yang dimuat dalam Postra Nomor 04 ( Jakarta : Institute For Social institutions Studies (ISIS) Mei 2002), h. 51

16، Kita akan membangun sebuah negara bagi semuanya, ... tidak hanya untuk golongan tertentu, tidak juga untuk para aristocrat dan orang kaya. Kita akan membangun sebuah negara yang didukung oleh kita semua, semua untuk semua. Tidak untuk kelompok Kristen, tidak untuk kelompok muslim,... tetapi sebuah Negara untuk semua bangsa Indonesia”. Ellyasa, Postra, Ibid., h. 52 
bahwa cita-cita kemerdekaan Indonesia merupakan salah satu cita-cita perjuangan umat Islam. Demikian pula pencapaian kemerdekaan Indonesia merupakan bagian tidak terpisahkan dari perjuangan Islam untuk menerapkan ajaran dan syari'at Islam. Untuk menandaskan argumentasinya, ia mengatakan bahwa umat Islam merupakan kelompok mayoritas yang berperan dalam perjuangan kemerdekaan. Perjuangan umst Islam menjadi benang merah dalam sulaman sejarah tanah air. ${ }^{17}$

Konflik idiologis untuk merumuskan dasar Negara akhirnya semakin tajam dan seru. Bagi kelompok Islam, Pancasila yang diusulkan Soekarno tidak merasa perlu ditanggapi, selain karena hanya kumpulan prinsip-prinsip juga karena resistensi kelompok Islam sendiri terlebih ketika Soekarno memeras usulannya menjadi trisila. Selanjutnya kelompok nasionalis menuntut modifikasi Pancasila itu agar diterima oleh kelompok Islam. Dari sinilah terbentuk komisi kecil yang kemudian popular disebut dengan komisi sembilan, yang salah satunya melahirkan kesepakatan yang disebut Piagam Jakarta. ${ }^{18}$

Sehari setelah Proklamasi kemerdekaan, kawasan bagian Timur, yang didominasi pemeluk Kristen dan Katolik, atas pimpinan A.A Maramis, mengancam akan memisahkan diri apabila Piagam Jakarta tetap dipakai. Dalam situasi genting seperti itu, Moh.Hatta mengundang Ki Bagus Hadikusumo, Wahid Hasyim, Kasman Singodimejo dan Teuku Hasan untuk membahas masalah crucial yang terjadi. Dalam pertemuan yang berlangsung hanya 16 menit itu, atas nama persatuan dan agar sebagai bangsa tidak terpecah-pecah maka kalimat yang

\footnotetext{
${ }^{17}$ Perhatikan Isa Anshari, Tentang Dasar Negara Republik Indonesia Dlam Konstituante, Vo.II, (Bandung: Konstituante Republik Indonesia, 1958), h. 179. Perhatikan pula Nurcholish Madjid, Islam Agama Kemanusiaan Membangun Tradisi dan Visi Baru Islam Indonesia (Cet. I; Jakarta: Paramadina, 1995, h. 4-5

${ }^{18}$ Rumusan lengkapnya sebagai berikut: (1) Ketuhanan dengan mejalankan syari'at Islam bagi pemeluk-pemeluknya, (2) Kemanusiaan yang adil dan beradab, (3) Persatuan Indonesia, (4) Kerakyatan yang dipimpin oleh hikmah dalam permusyawaratan perwakilan., (5) Keadilan sosial bagi seluruh rakyat Indonesia. Rumusan Piagam Jakarta inilah yang sekarang sedang menjadi agenda politik Partai Persatuan Pembangunan (PPP)dan Partai Bulan Bintang (PBB) dalam proses amandemen pasal 29 UUD 1945, terutama pada masa sidang tahun 2000-2002. Postra, Ibid., h. 54
} 
"Islami” dalam Pembukaan dan Batang Tubuh UUD 45 diganti. Rumusannya kemudian menjadi Ketuhanan Yang Maha Esa. ${ }^{19}$

Pada dekade mutakhir wacana ijtihad politik tersebut muncul kembali dalam memperjuangkan aspirasi politik umat Islam. Amandemen UUD 45 merupakan peluang bagi paratai Islam seperti; $\mathrm{PPP}^{20}$ dan $\mathrm{PBB}$, untuk memunculkan kembali wacana dan perjuangan politik untuk memasukkan kembali Piagam Jakarta terutama pada pasal 29 UUD 1945.

c. Piagam Madinah.

Ketika Nabi Saw, sampai di Madinah, beliau ingin menyatukan masyarakat Madinah di bawah kekuasaannya. Maksudnya tak lain adalah agar memiliki kekuatan sosial dan berguna bagi perkembangan Islam selanjutnya. Formula atau kebijakan strategi sosial politik yang dilakukan Rasulullah pertama kali yaitu melakukan dua hal penting; pertama, menjajaki komposisi demografis agama dan sosial dari penduduk Madinah. Kedua, Nabi melakukan sensus penduduk. Menurut data terakhir ditemukan 10 ribu penduduk: 1.500 kaum Muslimin, 4.000 Yahudi, dan 4.500 kaum Musyrikin. ${ }^{21}$ Dilihat dari angka ini, kaum Muslimin hanya $15 \%$ dari total jumlah penduduk. Itu artinya, kaum Muslimin merupakan komunitas minoritas. Dalam mengemban misinya untuk merebut dan menguasai Madinah, beliau, baik sebagai Nabi dan Rasul maupun

\footnotetext{
${ }^{19}$ Alamsyah Ratuprawira Negara, sewaktu menjadi menteri agama menyebutkan pembuangan kalimat islamis itu sebagai wujud dari pengorbanan umat Islam Indonesia untuk persatuan dan kesatuan bangsa.

${ }^{20}$ Pemandangan umum Fraksi Partai Persatuan Pembangunan Majelis Permusyawaratan Rakyat Republik Indonesia terhadap Hasil-hasil Badan Pekerja MPR-RI tentang Perubahan Kedua Undang-Undang Dasar Negara Republik Indonesia tahun 1945 dan Rancangan-0rancangan Ketetapan Majelis Permusywaratan Rakyat Republik Indonesia Lainyya, disampaikan pada Sidang Paripurna Sidang Tahunan MPR-RI pada tanggal 10 Agustus 2000. Postra, Ibid., h. 58

${ }^{21}$ Lihat Ali Bulac, "Piagam Madinah" dalam Charlez Kurzman (ed), Wacana Islam Liberal: Pemikiran Islam Kontemporer tentang Isu-isu Global ( Jakarta: Paramadina, 2001 ), h. 265-266
} 
sebagai negarawan haruslah melakukan ijtihad politik dengan menyususn kebijakan-kebijakan strategis untuk mencapai tujuan.

Dari kenyataan di atas, Nabi menjumpai tiga komunitas agama: Muslimin, Yahudi, dan Musyrikin. Muslimin terdiri dari Muhajirin dan Anshar; muhajirin terdiri dari Bani Hasyim dan Bani Muththalib, sementara Anshar terdiri dari suku Aus dan Khazraj. Yahudi terdiri dari Banu Qainuqa, Banu Nadhir, dan Banu Quraizhah. Sedangkan musyrikin adalah masyarakat Arab yang menyembah berhala (paganisme) dan kepercayaan lama. Ini artinya, Nabi menghadapi masyarakat yang majemuk, multi agama dan multi etnik. Tindakan pertama yang dilakukan Nabi adalah mempersaudarakan antara kaum Muslimin sendiri, yaitu anatara Muhajirin dan Anshar di rumah Anas Ibn Malik. ${ }^{22}$

Setelah persaudaraan dan persatuan antara kaum Muslimin tercapai, Nabi melaksanakan langkah keduanya dalam rangka menyatukan semua komunitas yang ada di Madinah, yaitu mengadakan perjanjian dengan Yahudi atas dasar aliansi dan kebebasan beragama. ${ }^{23}$ Tercapainya perjanjian ini, kekuatan sosial politik Madinah berada di bawah kekuasaan penuh Rasulullah. Perjanjian Nabi ini secara formal ditulis dalam sebuah naskah yang dikenal dengan "Piagam Madinah" (al-Shahifah al-Madinah atau al-Mitsaq al-Madinah).

Mengenai isi pokok atau prinsip-prinsp yang terdapat di dalam konstitusi Piagam Madinah yang terdiri dari 47 pasal, para ahli yang mengkajinya berbeda dalam membuat rumusannya.

Muhammad Khalid merumuskan 8 prinsip. 1). Kaum Muhajirin dan Ansar serta siapa saja yang ikut berjuang bersama adalah umat yang satu. 2). Orang-orang mukmin harus bersatu menghadapi orang bersalah dan mendurhaka meskipun anak mereka sendiri. 3). Jaminan Tuhan hanya satu

\footnotetext{
${ }^{22}$ Baca lebih lanjut dalam Abu al-Fida Ismail Ibn Katsir, al-Bidayat Wa al-Nihayat, Juz 2 ( Cet. I. Kairo: Daar al-Taqwa, 1420 H/1999 M) h. 231

${ }^{23}$ Muhammad Husain Haikal , Muhammad, (Kairo: al-Hayah al-Mishriyyah al-'Ammat Li al-Kitab, 2000), h. 238
} 
dan sama untuk semua melindungi orang-orang kecil. 4). Orang-orang mukmin harus saling membela di antara mereka dan membela golongan lain, dan siapa saja kaum Yahudi yang mengikuti mereka berhak memperoleh pembelaan dan bantuan seperti yang diperoleh orang muslim. 5). Perdamaian kaum muslim itu adalah satu. 6). Bila terjadi persengketaan di antara rakyat yang beriman maka penyelesaiannya dikembalikan kepada (hukum) Tuhan dan kepada Muhammad sebagai kepala Negara. 7). Kaum Yahudi adalah umat yang satu bersama kaum muslim. Mereka bebas memeluk agama mereka. 8). Sesungguhnya tetangga adalah seperti diri kita sendiri, tidak boleh dilanggar haknya dan tidak boleh berbuat kesalahan kepadanya. ${ }^{24}$

Sementara itu, Muhammad Jalal al-Din Surur juga merumuskannya ke dalam 8 prinsip.

1). Seluruh kaum muslimin adalah umat yang satu. 2). Masyarakat Islam dibentuk sebagai masyarakat yang solider dan kolektif. 3). Mengakui hakhak asasi kaum Yahudi dan mendorong mereka agar masuk Islam. 4). Kebebasan beragama bagi kaum Yahudi. 5). Mengembalikan segala masalah dan perselisihan kepada Nabi Muhammad sebagai kepala Negara. 6). Memperkuat pertahanan dan bersikap waspada terhadap musuh. 7). Pertahanan Negara adalah tanggung jawab seluruh warga Negara. 8). Kota madinah sebagai ibukota Negara harus dipertahankan dan dijunjung tinggi kehormatannya. ${ }^{25}$

Sedangkan Hasan Ibrahim Hasan merumuskan 4 prinsip:

1). Seluruh kaum muslim, dari berbagai golongan adalah satu umat yang bersatu. 2). Saling tolong menolong dan saling melindungi di antara rakyat yang baru itu atas dasar keagamaan. 3). Masyarakat dan Negara mewajibkan atas setiap rakyat untuk mempertahankan keamanan dan melindunginya dari serangan musuh. 4). Persamaan dan kebebasan bagi

${ }^{24}$ Lihat Muhammad Khalid, Khatam al-Nabiyyin, (Al-Qahirat, 1955), h.116

25 Suyuthi Pulungan, Prinsip-Prinsip Pemerintahan dalam Piagam Madinah, (Jakarta: PT. Raja Grafindo Persada, 1994), h. 118 
kaum Yahudi dan pemeluk-pemeluk agama lainnya di dalam urusan dunia bersama kaum muslim. ${ }^{26}$

Menurut Montgomery Watt, hal-hal terpenting dari konstitusi itu yang menggambarkan bentuk Negara, fungsi dan hak kepala Negara adalah lima poin berikut.

1). Orang-orang beriman dan orang-orang yang tergantung dengan mereka merupakan suatu komunitas (ummat). 2). Setiap suku atau bagian daripadanya berrtanggung jawab atas harta rampasan dan uang tebusan atas nama setiap anggotanya. 3). Para anggota masyarakat hendaknya menunjukkan solidaritas yang kuat melawan tindak kriminal dan tidak mendukung tindakan kriminal sekalipun itu keluarga dekatnya, yang tindakannya itu berkaitan dengan anggota masyarakat lainnya. 4). Para anggota masyarakat hendaknya menunjukkan solidaritas yang kompak dalam menghadapi orang-orang yang tidak beriman, baik dalam keadaan damai maupun perang, dan juga solidaritas dalam memberikan perlindungan kepada tetangga. 5). Kaum Yahudi yang berasal dari berbagai kelompok adalah milik masyarakat dan mereka memelihara agama mereka sendiri. Mereka dan orang-orang muslim saling memberikan bantuan (termasuk bantuan militer) antara satu dengan yang lainnya bila diperlukan. ${ }^{27}$

Banyak komitmen hidup berbangsa dan bernegara terdapat dalam dokumen Piagam Madinah tersebut, antara lain komitmen atau kesadaran terhadap pluralitas dengan tegas disebutkan, "Kaum Yahudi bebas menjalankan agama mereka sebagaimana umat Islam bebas menjalankan agama mereka." ${ }^{28}$ Karena kebebasan sebagaimana yang tertuang dalam Piagam ini, Munawir Sadzali menilai Piagam Madinah sebagai konstitusi Negara Islam pertama yang tidak menyebutkan agama Negara. ${ }^{29}$ Bahkan Nurcholish Madjid mengatakan, bunyi

${ }^{26}$ Hasan Ibrahium Hasan, Tarikh al-Islam, juz 1 ( Maktabah al-Nahdhat al-mishriyyat, Kairo, 1979), h. 103

${ }^{27}$ Watt, Islamic Political Thought, (Edinburgh University Press, Edinburgh, 1968), h. 5

${ }^{28}$ Diktum kebebasan beragama dalam Piagam ini relevan dengabn firman Allah dalam Q.S. al-Kafirun, ayat 6.

${ }^{29}$ Munawir Syadzali, Islam and Governmental Syistem: Teachings, History and Reflections (Jakarta: INIS, 1991), h. 12 
naskah Konstitusi itu sangat menarik. Ia memuat pokok-pokok pikiran yang dari sudut tinjauan modernpun mengagumkan. Ini berarti Negara mengakui semua agama dan tidak memaksakan pada paham satu agama saja. Prinsipnya adalah supremasi terhadap praktik ibadah setiap pemeluk agama.

Dengan lahirnya Piagam Madinah ini, ${ }^{30}$ sesungguyhnya Rasulullah telah melakukan lompatan ijtihad politik yang jauh ke depan yang luar biasa. Ia menjadi pijakan untuk realisasi proyek sosial yang pluralis. Yaitu sebuah masyarakat multi religius dan multi etnis. ${ }^{31}$ Piagam Madinah menjadi pijakan hidup bersama dalam satu komunitas bangsa. Dan dalam perspektif ke depan, telah melahirkan sebuah tatanan warga bangsa yang egaliter, partisipatif, dan demokratis.

\section{PENUTUP/KESIMPULAN}

Bertolak dari diskripsi beberapa postulat pemikiran di atas, maka dapatlah ditegaskan beberapa kesimpulan sebagai berikut:

1. Konsep ijtihad yang sangat penting kedudukannya dalam diskursus Fiqh Islam klasik, ternyata tidak hanya dapat ditempuh dan diterapkan pada wilayah fiqh ansich ( misalnya persoalan hukum peribadatan keagamaan), tetapi juga dapat diterapkan untuk melakukan istinbath membuat dan menetapkan konstitusi Negara pada wilayah sosial politik kenegaraan.

2. Di Indonesia, ada beberapa dokumentasi sejarah perjuangan politik, yang telah dipersembahkan oleh para "mujtahid politik kenegaraan antara lain penyusunan rancangan Pembukaan Undang-Undang Dasar 45 oleh

30 Naskah Piagam Madinah ditulis secara lengkap oleh Ibnu Hisyam (w. 218 H), sejarawan Islam Klasik dari Persia, dalam Kitabnya al-sirah al-Nabawiyyah dan ia membaginya menjadi 47 pasal. Lihat Abu Muhammad Abd al-Malik Ibn Hisyam al-Mu'aqqiry, al-Sirah alNabawiyyah, tahqiq: Sayyid Muhammad al-liham, (Beirut: Daar al-Fikr, $2001 \mathrm{M} / 1421 \mathrm{H}$ ) jilid II, h. 111-113. Kutipan teks Piagam Madinah dalam bahasa Indonesia dinukil dari Abdul Aziz Dahlan (et.al), Ensiklopedi hukum Islam, Jilid II, ( Cet. I. Jakarta: PT. Ichtiar Baru Van Hoeve, 1997 ) h. 1029-1031

${ }^{31}$ Munawir Syadzali, Islam and Governmental Syistem...Ibid., 
BPUPKI atas pimpinan Widiodiningrat, rumusan Piagam Jakarta oleh Panitia sembilan atas pimpinan soekarno, yang kemudian melahirkan UUD 1945 yang teridiri dari 37 pasal sebagai Konstitusi Negara, dan Pancasila yang terdiri dari 5 sila sebagai Falsafah Idiologi Negara.

3. Di dunia Islam, terutama pada periode Rasulullah Saw, ketika hijrah ke Madinah, Rasulullah membuat komitmen politik berbangsa dan bernegara yang melibatkan berbagai lapisan etnis, suku dan agama di Madinah. Komitmen politik itu disebut dengan Shahifah Madinah atau Watsiqah Madinah (piagam Madinah), yang terdiri dari 47 pasal sebagai dasar hidup bersama berbangsa dan bernegara. Sampai masa kini, pada dunia yang sangat modern, Piagam Madinah masih tetap dianggap sebagai ijtihad monumental politik yang paling modern, yang pernah dilakukan oleh Nabi Muhammad Saw.

DAFTAR PUSTAKA

Al-Fairuzzabadi Al-Qamus al-Muhith (Mesir: al-Halab, 1952 ).

Abu Zahrah, Muhammad,Ushul al-Fiqh, (Dar al-Fikr al-Arabi,1377 H / 1958 M).

Al-Isfahani, al-Raghib, Mufradaat al-Fazh al-Quran, (Cet. Pertama: Beirut Daar Al-Qalam, 1992 M)

Al-Marbawy, Muhammad Idris, Qamus Idris al-Marbawy Araby Malayu, ( Singapura: Daar al-Ulum al-Islamiah, $1353 \mathrm{H}$ )

Anshari, Isa, Tentang Dasar Negara Republik Indonesia Dlam Konstituante, Vo.II, ( Bandung: Konstituante Republik Indonesia, 1958 ) 
Bulac, Ali, "Piagam Madinah" dalam Charlez Kurzman (ed), Wacana Islam Liberal: Pemikiran Islam Kontemporer tentang Isu-isu Global ( Jakarta: Paramadina, 2001 )

Dahlan, Abdul Aziz, (et.al), Ensiklopedi hukum Islam, Jilid II, ( Cet. I. Jakarta: PT. Ichtiar Baru Van Hoeve, 1997 )

Dewan Redaksi Ensiklopedi Islam, jilid 2 ( Cet. III; Jakarta : PT. Ichtiar Baru Van Hoeve, 1994 )

Fazlur Rahman, The Islamic Consept of State, dalam John J. Donohue dan L. Esposito, (eds.) Islam in Transition, Muslim Perspective, ( Oxford University Press, New York, 1982 )

Haikal, Muhammad Husain, Muhammad, (Kairo: al-Hayah al-Mishriyyah al'Ammat Li al-Kitab, 2000)

Hasan, Ibrahim Hasan, Tarikh al-Islam, juz 1 (Kairo: Maktabah al-Nahdhat alMishriyyat, 1979)

Iqbal, Sir Muhammad, Reconstruction of Religions Though In Islam, kitab bavan, terjemahan, (India, 1981).

Ismail Ibn Katsir, Abu al-Fida, al-Bidayat Wa al-Nihayat, Juz 2 ( Cet. I. Kairo: Daar al-Taqwa, 1420 H/1999 M)

Ibnu Hisyam (w. 218 H) al-sirah al-Nabawiyyah Abu Muhammad Abd al-Malik Ibn Hisyam al-Mu'aqqiry, al-Sirah al-Nabawiyyah, tahqiq: Sayyid Muhammad alliham, Jilid II, (Beirut: Daar al-Fikr, $2001 \mathrm{M} / 1421 \mathrm{H}$ )

Ibn Taimiah, Majmu' Fatawaa pada pembahasan Kitab al-Tasawwuf, juz 3 (Beirut : Dar al-Arabiah, 1418 H / 1997 M)

Khalid, Muhammad, Khatam al-Nabiyyin, (Al-Qahirat, 1955)

KH Darwis, Ellyasa, Amandemen dan Perebutan Makna Pasal 29 UUD 45 Suatu Penghampiran Histories -Struktural, yang dimuat dalam Postra Nomor 04 ( Jakarta : Institute For Social institutions Studies (ISIS) Mei 2002)

Madjid, Nurcholish, Agama dan Politik dalam Islam, Jurnal Pemikiran Islam Paramadina, Volume I Nomor 1 ( Jakarta; Paramadina, 1998 ) h. 49 , Islam Agama Kemanusiaan Membangun Tradisi dan Visi

Baru Islam Indonesia (Cet. I; Jakarta: Paramadina, 1995)

Michael Hart Seratus Tokoh Dunia, ( Jakarta: Bonaputra, 1999) 
M. Shodiq, Kamus Istilah Agama, Edisi khusus, (Jakarta : Bonaciptama, 1991)

Ma'luf, Lois, Al-munjid Fi al-Lughah Wa al-A'lam, (Beirut: Daar al-Qalam, $1411 \mathrm{H} / 1991 \mathrm{M})$

Pulungan, J. Suyuthi, Prinsip-prinsip pemerintahan dalam Piagam Madinah Ditinjau dari Pandangan Al-Quran, ( Jakarta: Raja Grafindo kerjasama dengan LSIK Jakarta, 1994 )

Syadzali, Munawir, Islam and Governmental Syistem: Teachings, History and Reflections (Jakarta: INIS, 1991)

Sukardja, Ahmad, Piagam Madinah Dan Undang-Undang Dasar 1945 Kajian Perbandingan Tentang Dasar Hidup Bersama Dalam Masyarakat Yang Majemuk ( Cet. Pertama; Jakarta: UI-Press, 1995 ), h. 43

Soekarno, "Lahirnya Pancasila", dalam Pancasila Dasar Negara, ( Jakarta: Intidaya Press, 1986), h.144-145

Wahid, Salahuddin, "Dinamika Hubungan Islam dan Negara Di Indonesia”, Tashwirul Afkar Jurnal Refleksi Pemikiran Keagamaan dan Kebudayaan (Edisi Khusus; Jakarta: Lembaga Kajian dan Pengembangan Sumberdayamanusia ( LAKPESDAM NU kerjasama dengan DEPARTEMEN AGAMA RI, 2004 )

Watt, W.Montgomery, Islamic Political Thought, (Edinburgh University Press, Edinburgh, 1968) 